\title{
Muhuraida: entre história e ficção
}

\section{Yurgel Pantoja Caldas*}

\begin{abstract}
Resumo: Este trabalho refere-se ao poema épico do militar português Henrique João Wilkens, intitulado Muhuraida ou o triunfo da fé (manuscrito de 1785) considerado o primeiro poema sobre a Amazônia -, que trata em sua ação da "inteira conversão e reconciliação da grande e feroz nação do gentio Mura", como revela trecho de seu longo subtítulo. Levando em consideração os motivos históricos e os místicos da referida pacificação e conseqüente conversão dos Mura ao Catolicismo, nosso intuito é mostrar como Henrique João Wilkens utiliza relatos, documentos e informações históricas para compor sua ficção, e como Muhuraida serviria para fixar uma imagem demoníaca em relação aos Mura, o que também seria apropriado pelo discurso histórico posterior à publicação do poema, em 1819.
\end{abstract}

\begin{abstract}
This work deals with the epic poem by the Portuguese military man Henrique João Wilkens, entitled Muhuraida or the triumph of the faith (1785) - considered the first poem on the Amazon -, whose action represents the "entire conversion and reconciliation of the great fierce nation of the heathen people called the Muras", as one can realize from its long subheading. Taking into consideration the historical and mystic reasons that account for the aforesaid pacification and the following conversion of the Muras to Catholicism, this paper aims to point out how the Muhuraida's author makes use of stories, documents and historical information to compose his fiction, and also how Muhuraida could serve to establish a demonic image concerning the Mura people, which would also match the historical speech after the issuing of this poem, in 1819.
\end{abstract}

Keywords: Amazon; Mura; History; War.

O poema heróico Muhuraida ou o triunfo da fé (WILKENS, 1993), do engenheiro militar português Henrique João Wilkens - cujo manuscrito data de 1785, sendo, entretanto, de 1819 a primeira edição, a cargo do padre português Cypriano Pereira Alho -, enfoca as condições da rendição da nação indígena Mura e o processo que a levou à conversão à fé católica, ao mesmo tempo em que revela a capacidade de organização indígena na defesa de seus próprios interesses, como o aspecto sagrado de seu território. O poema também pode ser visto como um dos desdobramentos do processo de "limpeza étnica" enquanto estratégia do colonizador para garantir a expansão política e econômica de Portugal no decorrer do século XVIII.

O processo de eliminação do outro - prática comum no discurso militar colonial, que impunha a "civilização" do europeu à "barbárie" do nativo americano - ficou durante muito tempo abrigado sob o manto oficial das chamadas "guerras justas" de que os Mura foram

\footnotetext{
* Yurgel Pantoja Caldas é professor na Universidade Federal do Amapá.
} 
vítimas, sendo considerados como índios incivilizáveis em função de seu caráter "bárbaro" que não permitia a expansão geográfica através do mapeamento e da conseqüente demarcação do território referente à capitania do Rio Negro, nem o desenvolvimento econômico da região, cuja estrutura estava sendo levada adiante por meio das feitorias leigas que a política de Sebastião José de Carvalho e Melo (Marquês de Pombal) implantava no norte do Brasil.

Pode-se considerar que os prováveis motivos da "rendição" dos Mura tenham sido a sequiência de epidemias ocasionadas pelos contatos com os brancos e uma sangrenta guerra travada contra a nação Mundurucu, além, é claro, da política constante de guerras de extermínio implementada pela administração colonial contra os índios. Porém é outro o motivo da conversão mura que chama a atenção de Wilkens em sua narrativa: a explicação místico-religiosa, cujo agente é o governador das capitanias do Grão-Pará e Rio Negro, João Pereira Caldas - operador do "milagre" dessa conversão religiosa: "para quem, como Vossa Excelência, não foi mero espectador, mas sim, depois de Deus, o primeiro motor e agente dos oportunos meios que este fim interessante ao serviço de Deus e da Soberana conseguiram completamente" (WILKENS, 1993, p. 89). A rendição dos Mura, nos termos da paz, de tão surpreendente para as circunstâncias políticas da época, revela, pois, a crença de que o fato tenha sido mesmo uma obra divina.

Os Mura estão inseridos num contexto que coincide com o último ciclo de desenvolvimento daquele período em que surge o Tratado de Madri de 1750 para redefinir as fronteiras portuguesas e espanholas em territórios sul-americanos pleiteados pelos dois reinos. Após o Tratado, o regime imperial vê-se diante de um complexo desafio: a implantação de uma política moderna de desenvolvimento para aquela que tempos mais tarde seria conhecida como a região amazônica.

Entra em cena, então, o projeto pombalino de administração aplicado às capitanias do norte, através da exploração agrícola com influxos capitalistas - projeto financiado pela Companhia Geral de Comércio do Grão-Pará e Maranhão e administrado burocraticamente por diretorias estatais que explorariam uma reserva de mão-de-obra assalariada. Criar tal reserva de mão-de-obra significava naquele momento - com o processo de decadência da economia mineira e a ascensão comercial da Inglaterra e da Holanda através de suas respectivas colônias - estabelecer condições efetivas para a proletarização das comunidades indígenas da região.

Quando se chega, no entanto, ao texto ficcional de Wilkens sobre os Mura, o que se nota é uma tentativa sistemática de esvaziar a complexidade dos vários conflitos existentes em 
função de uma homogeneização que se quer especialmente sem fissuras, como no penúltimo canto do referido épico amazônico, quando é narrada a preparação do aldeamento indígena:

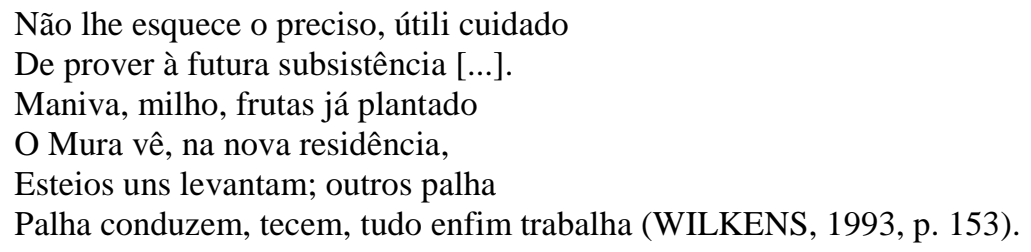

Outro trecho do poema que exemplifica o desejo do autor em demarcar uma narrativa homogênea em detrimento dos conflitos existentes na conversão dos Mura pode ser revelado na apoteótica estrofe final, que resume bem o espírito colonial na Amazônia, durante o século XVIII:

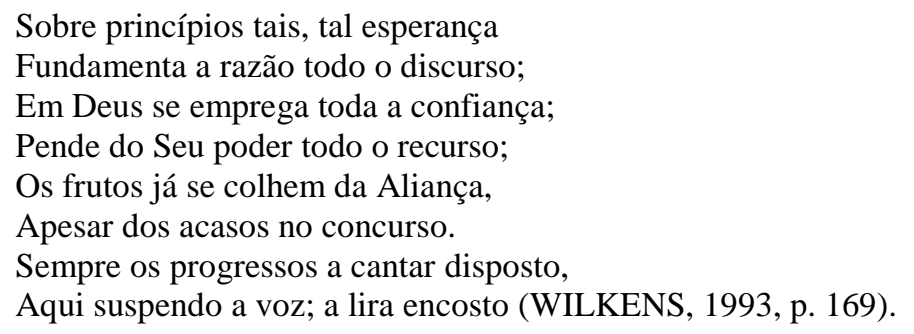

Obviamente que o lugar de enunciação de Muhuraida nos ajuda a entender esse processo de forma mais clara, se considerarmos as funções exercidas por Henrique João Wilkens: engenheiro militar a serviço de Portugal para compor comissões de limites geográficos, além de fazer parte de grupos que se empenharam na formação de uma reserva de mão-de-obra cabocla e indígena para o chamado progresso da capitania. Portanto, não há como negar o caráter de legitimação do império português sobre a colônia brasileira, tendo em vista o longo período de crise do projeto colonizador ibérico, que se agravava e atingia o seu auge na segunda metade do século XVIII. Uma nota de Wilkens ao verso "Se avista enfim o porto procurado" (WILKENS, 1993, p. 137) diz o seguinte: "Novidade causou na verdade [...] ver aqueles mesmos muras [...] procurar debaixo da maior paz e confiança os mesmos moradores [antes vítimas daqueles índios]; foi igual a surpresa e natural [...] a uniformidade dos sentimentos em todos [grifo nosso]" (WILKENS, 1993, p. 137), o que comprova o desejo da unificação pela conversão mura.

Nesse viés contemporizador, não há na narrativa de Wilkens uma cena de batalha, nem um conflito armado, sequer um duelo físico - a não ser alguns versos que descrevem os ataques muras antes da chegada dos heróis portugueses (agentes do milagre da conversão indígena):

Daqui de agudas flechas um chuveiro

Por entre espessos ramos, despedido,

Traspassa o navegante e o remeiro, 
Ou do terror da morte possuído,

O faz precipitar na onda, primeiro

Preferindo deixar tudo perdido,

Que expor a amada vida à morte certa,

Em ara impura, involuntária oferta (WILKENS, 1993, p. 107).

O que há é a narração da conversão indígena "espontânea" por meio de um discurso colonizador que promete aos Mura, além da previsível libertação das almas e de donativos a partir da aceitação das condições coloniais, alguma participação nas relações comerciais que poderiam se estabelecer por meio do tratado de paz a ser firmado por aqueles gentios:

Tereis nos povos vossos numerosos

Abundantes colheitas sazonadas,

Vereis nos portos vossos vantajosos

Comércios florescer, e procuradas

Serão as armas vossas; poderosos

Enfim sereis, amadas, invejadas

Serão vossas venturas; finalmente

Podereis felizes ser eternamente (WILKENS, 1993, p. 127).

Outra relevante questão para os esforços em se converter à tribo "bárbara" é de ordem econômica, como aponta a "Introdução" de Adelaide Engrácia de Oliveira aos Autos da devassa contra os índios Mura do rio Madeira e nações do rio Tocantins (1738-1739) (CEDEAM, 1986) - documento considerado inaugural em se tratando de autos de devassa contra índios na Amazônia". Adelaide de Oliveira afirma, nesse caso, que é "muito significativo que fosse pedida uma guerra contra os índios Mura do rio Madeira, uma vez que esse era o caminho que conduzia às minas de Vila Bela e Cuiabá, em Mato Grosso, e que fosse um rio onde havia surgido uma nova droga do sertão, o cacau" (CEDEAM, 1986, p. 5).

O texto de Wilkens, por outro lado, faz questão de reforçar apenas o caráter homogeneizador de todo esse processo de conversão dos Mura, inclusive negando a própria tradição do gênero épico que privilegia o conflito militar através de descrições de batalhas - o que é completamente apagado em Muhuraida, fazendo desse texto um épico estranho em um aspecto fundamental: a ausência de descrição de cenas militarmente heróicas do ponto de vista da tradição crítica brasileira dos séculos XIX e XX. Disso decorre talvez o enfraquecimento do texto em si como referência da primeira fase romântica brasileira diferentemente do que aconteceu com Caramuru (DURÃO, 1913) e O Uraguay (GAMA, 1995), antecessores de Muhuraida nesse processo de criação ficcional de uma certa identidade ao território nacional.

\footnotetext{
${ }^{1}$ Este texto - que havia sido descoberto em 1983 por um funcionário do Arquivo Histórico Ultramarino de Lisboa e trazido ao Brasil por João Renôr Ferreira de Carvalho, então pesquisador da CEDEAM (Comissão de Documentação e Estudos da Amazônia) - mostra uma das estratégias de colonização que prepara o terreno para os procedimentos da chamada "guerra justa" contra grupos indígenas que porventura impedissem o processo de expansão política, religiosa e/ou econômica de Portugal.
} 
Parece que a decisão de abrir mão de sua resistência às pressões militares e culturais da sociedade branca foi o resultado da debilitação progressiva por epidemias, crescentes influências não-indígenas e guerras implacáveis que contra os Mura travavam os Mundurucu, os quais avançavam do Madeira em direção a oeste. O governador geral João Pereira Caldas, a quem é dedicado o poema, aparece no texto como um dos agentes, conforme vimos no início, do milagre divino da conversão dos Mura. A dedicatória cita a memória daquele governador geral como evidência da autenticidade da narração através da experiência administrativa e da forte influência política do homenageado:

O conhecimento que Vossa Excelência tem completo deste Estado do Pará [...], sendo depois o criador do governo do Piauí, e tendo passado depois ao governo geral do Mato Grosso e Cuiabá, a ser encarregado da execução do Tratado Preliminar de Paz e Limites da Coroa de Portugal com Espanha [...] e a residir em Barcelos até maio de 1789, tendo Vossa Excelência já anteriormente estado na mesma vila [...] na ocasião das incompletas demarcações passadas; toda a razão subministra para Vossa Excelência [...] reconhecer poder a verdade dos fatos nestes versos relatados (WILKENS, 1993, p. 89).

Durante os cantos iniciais de Muhuraida, percebe-se que os índios Mura em muito se aproximam de uma conduta demoníaca, o que por si só justificaria uma ação religiosa pela retirada dos índios de tal condição malévola:

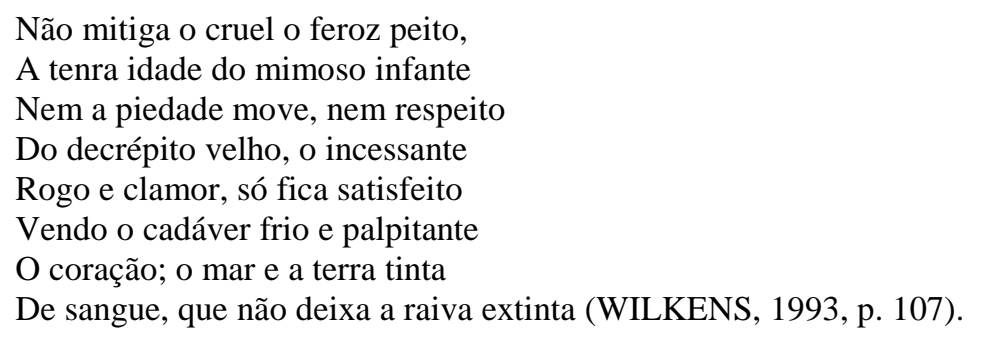

A crueldade, a impiedade e o desejo permanente de derramar o sangue alheio podem ser considerados traços malignos, reforçados pela perspectiva do discurso colonial exposta nos versos de Wilkens, o qual monta um quadro inicial apresentando o Mura como um ser inumano em que "Só de fereza na miséria abunda [e] Só os acidentes tem da humanidade" (WILKENS, 1993, p. 109). Bárbaros, impiedosos e animalescos, os Mura, assim como todos os gentios, estariam sob influência demoníaca, conforme nota do próprio Wilkens, em Muhuraida: "Ficção poética, mas que toda a aparência também tem de realidade e certeza, pois ao Inimigo comum do gênero humano seria sensível golpe a perda do Domínio Tirânico que ele tinha e tem neste [Mura] e nos mais gentios" (WILKENS, 1993, p. 159).

Trata-se, portanto, de uma peleja moral entre a fé católica e a irracionalidade bárbara dos índios em questão - já que no contexto geral do pensamento setecentista, ainda bastante influenciado pelo viés religioso, a falta de razão poderia estar relacionada à fatal ausência do Bem (Deus). Muhuraida aponta, assim, para um caminho que apresenta a violência sendo 
engendrada pela maldade dos índios Mura - fruto de seu próprio paganismo. Ou melhor, esse paganismo é quem cria a maldade que, por sua vez, amplia o caráter da violência praticada contra os brancos e índios não-Mura. Daí a necessidade da conversão/pacificação daquela população indígena.

Dessa forma, se por si só o termo "reconciliação" - extraído do subtítulo do poema de Wilkens $^{2}$ - é insuficiente para conferir coerência à narrativa, resta uma perspectiva bíblica em torno da idéia do homem natural em estado selvagem, da qual os Mura seriam herdeiros e teriam perdido sua condição de ingenuidade adâmica ao se voltarem contra as muitas tentativas de conversão, anteriores a 1784-5, período de concepção e produção de Muhuraida. Nesse caso, se a conversão mura ao Catolicismo não fosse empreendida, aqueles "bárbaros", enquanto representação do Mal (seres sob o domínio de Satanás), continuariam nas trevas do paganismo - sem (re)conhecer a autoridade do verdadeiro Deus, supremo e misericordioso -, com atitudes eminentemente malignas, vivendo na violência plena e destrutiva da barbárie.

No campo econômico, o progresso e a modernização das capitanias do norte do Brasil na segunda metade do século XVIII só teriam real caráter universalizante quando os índios aceitassem sobreviver da comercialização de mercadorias e do trabalho assalariado - que queria dizer, naquele momento, um trabalho em situação de semi-escravidão -, deixando de lado o modelo tradicional da cultura de subsistência da maioria das populações indígenas daquele período.

Com violenta hostilidade, historicamente os Mura sempre rechaçaram toda e qualquer possibilidade de assimilação pela cultura branca - justificativa determinante para inúmeras ações militares contra os Mura, como as chamadas "guerras justas". Parte desse contato conflitante entre europeus/colonos e nativos da região revela-se nos já mencionados Autos, o que reforça ainda mais o sentido negativo e violento do termo "bárbaro" aplicado aos Mura, de acordo com o seguinte trecho:

Está tudo infeccionado de uma nação de índios bárbaros chamados Mura, os quais andam tão insolentes que nestes anos próximos não somente tem morto a muitos índios remeiros das canoas [...] mas também [...] mataram e flecharam a muitos deles, sem mais causa que a sua braveza e malignidade, lhes tomaram todos os trastes (CEDEAM, 1986, p. 9).

\footnotetext{
${ }^{2}$ A íntegra do subtítulo de Muhuraida é a seguinte: "Ou o triunfo da fé na bem fundada esperança da inteira conversão e reconciliação da grande e feroz nação do gentio Mura. Poema heróico composto e compendiado em seis cantos, dedicado e oferecido ao ilustríssimo e excelentíssimo senhor João Pereira Caldas, do conselho de sua magestdade fidelíssima, alcaide-mor, comendador de S. Mamede de Troviscoso na Ordem de Cristo; governador e capitão general que era do Estado do Grão-Pará, e agora nomeado das capitanias de Mato Grosso e Cuiabá e nos distritos delas e deste Estado do Pará; encarregado da execução do Tratado Preliminar de Paz e Limites, por parte da mesma augustíssima rainha fidelíssima."
} 
A denúncia inicial desses Autos é afirmada num documento assinado pelo padre José de Souza, membro da Junta das Missões - apesar de ainda pairarem dúvidas a respeito da legitimidade sobre a declaração de guerra contra os Mura e, sobretudo, contra os índios do rio Tocantins

por não se saberem, em particular, as nações que impedem o comércio e infestam aquele rio; contudo, como entendo ser certo que algumas nações do dito rio tem feito as hostilidades que na devassa se referem, impedindo o trânsito aos portugueses, julgo se lhes poderá fazer guerra, procedendo primeiro averiguação individual das Nações criminosas (CEDEAM, 1986, p. 93).

Seria interessante notar os laços ideológicos entre alguns depoimentos dos Autos e certas passagens iniciais de Muhuraida a fim de que se monte um discurso afinado no sentido de condenar as ações indígenas de resistência, consideradas ofensivas ao plano iluminista de colonização amazônica. Assim, o trecho "que o gentio bárbaro chamado Mura do rio da Madeira tem feito várias mortes, assim a brancos como a negros que vão àquele rio à colheita de cacau, de sorte que é tanto o temor dos moradores desta cidade" (CEDEAM, 1986, p. 44-5) articula-se à primeira nota do autor do épico amazônico, que revela, em tom jurídico: "Do horroroso estrago e mortandade que os Mura fizeram no ano de 55 deste século [XVIII] [...] fui eu ocular testemunha; do que fizeram nas povoações do Solimões em 56 e 57, também vi; e da desolação em que tudo ficou, enchendo todos de horror" (WILKENS, 1993, p. 99). Nesses dois casos, tanto o depoimento dos Autos poderia estar contido no poema quanto a referida nota de Wilkens poderia ser parte integrante do processo judicial contra os Mura.

Diante da iminente declaração de guerra, o parecer do rei D. João V indicava, entretanto, a recusa do Estado em autorizar tal ação militar, como aponta a decisão do rei português: "me pareceu dizer-vos que não está em termos de se reputarem com justas e necessárias estas guerras" (CEDEAM, 1986, p. 163).

A negativa oficial do rei não impediu, porém, que se levassem a cabo sucessivos ataques contra os Mura, organizados por milícias particulares e por tropas coloniais, a tal ponto de o ouvidor da capitania do Rio Negro, um representante oficial da administração portuguesa na região norte, Francisco Xavier Ribeiro de Sampaio, liderar uma aberta campanha de extermínio contra aqueles índios. Nesse contexto, prevalecia uma acusação geral contra os Mura, baseada numa espécie de

$$
\begin{aligned}
& \text { proceso de diabolización de este gentío, en el cual la exageración, el vilipendio, la hipérbole, la } \\
& \text { traición, la 'mortandad', la piratería, constituían las palabras claves y los estigmas utilizados } \\
& \text { para trazar la caricatura y el perfil de la criatura maldita que era necesario eliminar } \\
& \text { (BENCHIMOL, 1990, p. 221). }
\end{aligned}
$$

Essa fixação de uma imagem demoníaca para os Mura é mostrada durante todo o século XVIII, não apenas com a presença de Muhuraida, mas ainda com outros documentos 
anteriores ou mesmo contemporâneos ao poema de Wilkens, dos quais ele provavelmente poderia ter se servido como fontes consultadas. Assim, ao lado de passagens de Muhuraidacomo a nota a seguir: "É bem constante como o gentio Mura barbaramente abusa das mulheres prisioneiras, e ainda depois de mortas, na ação de as cativar, à violência das flechas, não dispensando este horroroso costume, como distintivo da nação" (WILKENS, 1993, p. 109) -, convivem textos do referido ouvidor Francisco Xavier Ribeiro de Sampaio -

Conjecturo que se se não dá pronto e eficaz remédio para inteiramente profligar a destruir esta nação [Mura], que por sua natureza conserva cruel e irreconciliável inimizade com todas as mais nações, não exceptuando os [outros] índios; que nas suas guerras e assaltos usa a mais bárbara tirania, não perdoando aos mesmos mortos a quem cometeu inenarráveis crueldades, esfolando e rompendo os cadáveres (SAMPAIO, 1985, p. 85)

e também de Alexandre Rodrigues Ferreira, que escreveu sobre os Mura: "o desejo de se vingarem é tão cego e abruptado como o dos animais ferozes" (FERREIRA, 1974, p. 61).

Nos anos subseqüentes a 1740, ocorreram seguidos ataques contra os Mura, inclusive com a participação de nações rivais desses chamados "índios de corso", como os Maué, os Parintintin e os Mundurucu - estes, arqui-inimigos dos Mura. Tal situação beligerante, envolvendo diferentes populações, culminaria com a participação mura lutando contra o poder colonial, ao lado das milícias rebeldes, no movimento conhecido como Cabanagem (17351740) - revolta paraense de caráter popular contra a política imperialista brasileira. Nesse contexto, não seria demais considerar que algumas das nações inimigas dos Mura pudessem ter sido aliciadas pela administração colonial para lutarem ao lado das forças conservadoras e naturalmente contra os Mura, conforme sugere o trecho de uma carta do próprio João Pereira Caldas:

Sabia eu também já de carnagem que o outro gentio Mundurucu havia feito nos mesmos muras; e mal é que, reduzidos estes, se venham aqueles introduzir nesse rio e fazer o seu estabelecimento no Gutazes, para que se bem livre duns, não deixe de ficar sempre infestada doutros essa navegação (apud COUTINHO, in Revista do Instituto Histórico e Geográfico Brasileiro, tomo XXXVI, $1^{\text {a }}$ parte, 1873, p. 378-9).

Após o término da Cabanagem, a repressão colonial aos Mura continuou com fôlego renovado e, somada às constantes epidemias, criou-se um quadro de extermínio vertiginoso e até então inédito. A população mura decrescia de maneira assustadora a ponto de o Mapa Estatístico dos Aldeamentos dos Índios ter indicado, em 1856, a presença de 1.300 muras em toda a região referente ao atual Estado do Amazonas - dado alarmante e sintomático para um registro de um total de cerca de 60.000 indivíduos trinta anos antes.

Ainda assim, os Mura - confirmando sua tradição de resistência guerreira - envolvemse em vários conflitos até a luta contra os Parintintin, em 1863, que marca a última referência efetiva sobre os Mura em documentos do período, de acordo com as anotações de Carlos 
Moreira Neto: “A partir da última data [1863], os Mura não comparecem mais, senão incidentalmente, nos relatórios e nas preocupações oficiais, prova de que foram finalmente dominados ou sofreram tantas baixas que optaram pelo isolamento em regiões de refúgio" (WILKENS, 1993, p. 68). Moreira Neto continua informando que "isto parece ser confirmado pela situação de uma subtribo Mura, os Mura-Pirahã, que eram considerados, no século XIX, como os mais arredios e agressivos membros do grupo e que permanecem, ainda hoje, monolíngües" (WILKENS, 1993, p. 68).

Dados recentes da FUNAI (MOREIRA Neto, In WILKENS, 1993, p. 68-9) dão conta de que atualmente os Mura consistem numa população recenseada de cerca de 1.300 indivíduos fixados em algumas poucas áreas de municípios do Estado do Amazonas, como Autazes e Borba. Já os Mura-Pirahã contam com cerca de 130 índios localizados nos também municípios amazonenses de Humaitá e Manicoré.

A figura do índio, na construção de um cânone literário brasileiro, gira em torno do caráter de um herói nacional, pois ele fora o elemento eleito pelos escritores românticos brasileiros da chamada primeira geração (Nativista) como o símbolo que melhor poderia representar o aspecto telúrico (primeira metade do século XIX). Na conclusão de Guerra Mura no século XVIII: versos e versões, Marta Rosa Amoroso destaca que, "enquanto documento histórico, o poema [Muhuraida] é a voz de um dos agentes sociais envolvido no conflito do qual a redução dos Mura [...] foi a principal resultante" (AMOROSO, 2001, p. 171). A mesma autora arremata, logo em seguida, ao considerar que o poema de Wilkens "apresenta dados etnográficos, históricos e geográficos sobre a população Mura no século XVIII, numa versão semelhante àquela encontrada em outros documentos que registraram a vitória da colonização sobre os Mura” (AMOROSO, 2001, p. 171).

No panorama literário do Brasil, a segunda metade do século XVIII conta com as presenças marcantes de O Uraguay, de Basílio da Gama (1769), e do Caramuru, de Santa Rita Durão (1781), como os dois poemas épicos do período que mais revelam a necessidade de inserir como uma espécie de herói o elemento indígena com alguma importância nesse tipo de narrativa, já que ele passaria a ser protagonista. Escrito no mesmo período, e ao contrário do que sucedeu com os épicos acima citados, não há registros de referência ao poema Muhuraida nos textos críticos de ou sobre a corrente indianista do Romantismo.

Apesar de não fazer parte das leituras românticas do século XIX, Muhuraida (1785) consegue estabelecer uma narrativa em que o gênero épico - ao apontar para o engrandecimento de um povo, mas também revelar as crises internas da administração colonial no Brasil - se serve de apontamentos históricos, como os documentos dos Autos da 
devassa... para se constituir enquanto texto literário. No caminho inverso, a imagem histórica do índio Mura bárbaro e cruel, que aparece nos primeiros cantos do poema de Wilkens - em que pesem as notas do padre-editor Cypriano Pereira Alho, que tentam minimizar a barbaridade dos índios em função de uma leitura de seus hábitos culturais - é a que se cristalizou e foi tomada como dado histórico sobre o gentio da região do rio Madeira.

Na edição de 1819, o padre Cypriano Pereira alho, a propósito, insere algumas notas que não são de autoria de Wilkens, mas estão assinadas como sendo do próprio padre Alho como "A lança de que usam todos os índios do Amazonas é realmente muito boa, ainda que nada tenha de vistosa" (WILKENS, 1993, p. 189), ou “Os Uacaxi são hoje os povos de que se fez ou com que se fundou a povoação chamada Vila de Serpa, território fertilíssimo e abundantíssimo de tabaco" (WILKENS, 1993, p. 199) - e omite outras tantas, que constam do manuscrito de 1785, do autor de Muhuraida - como "Alvarães. Lugar, povoação não muito distante de Ega, na margem meridional do Solimões ou Amazonas; os índios e os moradores denominavam esta povoação com o nome de caiçara" (WILKENS, 1993, p. 155), ou

É bem constante e notório o caráter dos nossos índios do Estado do Pará, inteiramente despidos do estímulo da Ambição, passando mesmo inatentos ao uso de vestidos, vestes, sapatos, etc. Mas isto procede do vício da Criação e do abatimento em que os antigos conquistadores conservavam os índios todos (WILKENS, 1993, p. 103).

Das notas inseridas, algumas delas tratam da vida cultural da nação Mura, como o artesanato e a vida familiar, os costumes e as festas, a caça, a pesca e a coleta de alimentos.

E se, enfim, as estratégias narrativas expostas em Muhuraida - querendo ser, de um modo ou de outro, unificadoras, hegemônicas, indiferenciadas e amplas, para garantir uma melhor implantação do progresso civilizador - deixam vários espaços que podem ser preenchidos por uma visão crítica em torno das diversas contradições e fraturas presentes no interior do próprio discurso poético, é porque talvez essa nação que começa a se desenhar através desses enredos possa ser lida com o filtro histórico da indecisão e do atravessamento de várias forças que passam pelo discurso do poeta vivendo no Brasil, ainda colônia, mas com olhos, corações e mentes na Europa ocidental e metropolitana.

\section{Referências:}

AMOROSO, Marta Rosa. Guerra Mura no século XVIII: versos e versões. Campinas: Unicamp/IEL, 2001. 
BENCHIMOL, Samuel. Introducción a los "Autos da Devassa" de los indios Mura (1738), In CAMACHO, Roberto Pineda, ANGEL, Betariz Alzate (comps.). Los meandros de la historia en la Amazonía. Quito: Abya-Yala; Roma: MLAL, 1990, p. 215-66.

BENJAMIN, Walter. Obras escolhidas. Tradução de Sérgio Paulo Rouanet. São Paulo: Brasiliense, 1994 (vol. 1).

CANDIDO, Antonio. Formação da literatura brasileira. Belo Horizonte: Itatiaia, 1997 (2 vols.).

CEDEAM. Autos da devassa contra os índios Mura do rio Madeira e nações do rio Tocantins (1738-1739). Manaus: Universidade do Amazonas; Brasília: INL, 1986.

COUTINHO, Antonio Carlos da Fonseca. Notícias de voluntária redução de paz e amizade da feroz nação do gentio Mura nos anos de 1784, 1785 e 1786, do furriel comandante do destacamento do lugar de Santo Antonio de Imaripi, no rio Japurá, Revista do Instituto Histórico e Geográfico Brasileiro, Rio de Janeiro, tomo XXXVI, $1^{\text {a }}$ parte, p. 323-92, 1873.

DURÃO, Santa Rita. Caramuru. Rio de Janeiro: Livraria Garnier, 1913.

FAUSTINO, Mário. Evolução da poesia brasileira. Salvador: Fundação Casa de Jorge Amado, 1993.

FERREIRA, Alexandre Rodrigues. Viagem filosófica pelas capitanias do Grão-Pará, Rio Negro, Mato Grosso e Cuiabá. Brasília: Departamento Federal de Cultura/Departamento de Imprensa Nacional, 1974.

FRITZEN, Celdon. Muhuraida e as contradições da inserção esclarecida do outro, Estudos Portugueses e Africanos, Campinas, n³ 39, p. 119-35, jan.-jun. 2002.

GAMA, José Basílio da. O Uraguay. Rio de Janeiro: Fundação Biblioteca Nacional, 1995.

MENDONÇA, Marcos Carneiro de. A Amazônia na era pombalina: correspondência do governador Francisco Xavier de Mendonça Furtado. Rio de Janeiro: IHGB, 1963 (vol. 3).

MOREIRA Neto, Carlos de Araújo. Henrique João Wilkens e os índios Mura, In WILKENS, Henrique João. Muhuraida ou o triunfo da fé. Manaus: Universidade do Amazonas, Rio de Janeiro: Fundação Biblioteca Nacional, 1993, p. 33-81.

NIETZSCHE, Friedrich. Genealogia da moral. Trad. Paulo César de Souza. São Paulo: Companhia das Letras, 1998.

RAMINELLI, Ronald. Do conhecimento físico e moral dos povos: iconografia e taxionomia na Viagem Filosófica de Alexandre Rodrigues Ferreira. História, Ciências, Saúde. Niterói, vol. VIII, 2001, p. 969-92.

TEIXEIRA, Ivan (org.). Obras poéticas de Basílio da Gama. São Paulo: Edusp, 1996. 
TREECE, David H. Introdução crítica à Muhuraida, WILKENS, Henrique João. Muhuraida ou o triunfo da fé. Manaus: Universidade do Amazonas; Rio de Janeiro: Fundação Biblioteca Nacional, 1993, p. 11-31.

VAINFAS, Ronaldo. A heresia dos índios: catolicismo e rebeldia no Brasil colonial. São Paulo: Companhia das Letras, 1995.

VERÍSSIMO, José. História da literatura brasileira. Rio de Janeiro: Record, 1998.

VICENTINI, Yara. Cidade e história na Amazônia. Curitiba: Ed. UFPR, 2004.

WILKENS, Henrique João. Muhuraida ou o triunfo da fé. Manaus: Universidade do Amazonas; Rio de Janeiro: Fundação Biblioteca Nacional, 1993.

WRIGHT, Robin M. (org.). Transformando os deuses: os múltiplos sentidos da conversão entre os povos indígenas no Brasil. Campinas: Ed. Unicamp, 1999. 